\title{
Aspectos Inclusivos da Moda com Foco nas Pessoas com Deficiência Visual
}

Aspectos of Fashion Inclusive with focus on people with visual impairment

\section{Driélli Valério de Oliveira}

Aluno especial na Pós Graduação em Design FAAC Unesp drika.valerio@hotmail.com

\section{Laís Regina Faganello}

Graduação em Design de Moda pela Universidade Estadual de Maringá laisfaganello@hotmail.com

\section{Andressa Rossi}

Especialização em MBA em Moda Instituto Paranaense de Ensino dressa_rossi@hotmail.com

\section{Fausto Orsi Medola}

Professor Assistente Doutor - FAAC/UNESP fausto.medola@faac.unesp.br

\section{Luis Carlos Paschoarelli}

Livre-Docente em Design Ergonômico pela Universidade Estadual Paulista paschoarelli@faac.unesp.br 


\section{Aspectos Inclusivos da Moda com Foco nas Pessoas com Deficiência Visual}

Aspectos of Fashion Inclusive with focus on people with visual impairment

Driélli Valério de Oliveira, Laís Regina Faganello, Andressa Rossi, Fausto Orsi

Medola e Luis Carlos Paschoarelli

\section{Resumo}

Há um número elevado de pessoas com algum grau de deficiência visual no Brasil, as quais têm dificuldades em tarefas comuns do dia a dia como se vestir e escolher uma peça. Este trabalho propõe discutir os aspectos inclusivos aplicáveis ao design de moda para pessoas com deficiência visual, buscando fundamentar uma proposta de vestuário que contemple a autoestima, praticidade, conforto e autonomia destes usuários sem, entretanto, diferenciá-los dos consumidores em geral. As propostas são baseadas no design de superfície - por meio da aplicação de detalhes em relevo e braile - moda inclusiva e design universal.

Palavras - chave: Moda Inclusiva, Design de Superfície, Tecnologia Assistiva

\begin{abstract}
There is a large number of people with some degree of visual impairment in Brazil, which have difficulties in common tasks of everyday life, such as dressing and choosing a piece of cloth. This paper aims to discuss the inclusive aspects applicable to fashion design for visually impaired people, seeking to support a proposal of clothing that includes self-esteem, practicality, comfort and autonomy of users without, however, differentiate them from general consumers. The proposals are based on surface design - through the application of details in relief and Braille inclusive fashion and universal design.
\end{abstract}

Keywords: Inclusive Fashion, Surface Design, Assistive Technology 


\section{Introdução}

O Censo de 2010 revelou que cerca de 45 milhões de pessoas possuem algum tipo de deficiência, sendo que 35 milhões de pessoas possuem algum grau de comprometimento visual, sendo 582 mil cegos (IBGE, 2010). É um número alto, representa quase um quarto da população brasileira, uma parcela representativa de $18,7 \%$. Entretanto, ainda carece de um mercado que atenda as reais necessidades desta demanda.

Poucos estudos destacam a necessidade de uma abordagem inclusiva para o design de moda. Muitas pessoas com deficiência chegam a levar até duas horas para realizar atividades simples como vestir-se e, em muitos casos, acabam optando por ficar em casa, diminuindo sua autoestima.

As peças desenvolvidas para o público de pessoas com deficiência ou mobilidade reduzida costumam ter detalhes que facilitam o processo de vestir-se da pessoa com deficiência, assim como o processo de ajuda dos cuidadores e/ou familiares. No entanto, tais peças são úteis apenas para quem está na cadeira de rodas, ou quem usa sonda, impossibilitando a utilização de pessoas sem deficiência, com a mesma praticidade e funcionalidade. Portanto, a moda para pessoas com deficiência, ainda que favoreça alguns aspectos funcionais, não contempla os princípios da universalidade, uma vez que não possibilita o uso por todas as pessoas. Um bom exemplo são as calças com bolsos internos, que facilitam o processo de cateterismo (sondagem vertical), porém, não são confortáveis em andantes, nem tampouco esteticamente atraentes. Outro exemplo são os vestidos para cadeirantes que são colocados pela frente, abotoando atrás do pescoço, deixando as costas desnudas, o que também não é adequado para andantes, assim o que era pra ser denominada "moda inclusiva", deste modo, se torna "exclusivo" para pessoas com deficiência.

$\mathrm{O}$ presente estudo tem como objetivo discutir as relações entre moda e deficiência visual a partir de uma perspectiva inclusiva e, a partir desta reflexão, apresentar propostas de vestuário que favoreçam os aspectos funcionais sem, entretanto, diferenciar a peça, fazendo com que esta possa ser desejada e utilizada por todos os consumidores, e não apenas pelas pessoas com deficiência visual. 


\section{Design de Superfície}

O design trabalha com a criação, elaboração e desenvolvimento de projetos e estratégias que solucionem necessidades específicas, podendo estar relacionadas a algo que esteja em falta no mercado ou que irá agregar algum valor de cunho social e significativo. Possui a função de antecipar problemas, definir estratégias, gerar oportunidades e liderar projetos multidisciplinares. Dessa forma, o design torna-se elemento fundamental no desenvolvimento de novos produtos, através da escolha de cores, formas, identidade e aspectos conceituais. O campo do design é fragmentado em diversas áreas, entre elas o Design Gráfico, Design de Produto, Design de Moda, Design Digital, Web Design, Design de Móveis e Design de Superfície (CALDERÓN, 2010).

Dentro das ramificações do design, o Design de superfície é o que projeta texturas bi e tridimensionais para diferentes superfícies, buscando soluções estéticas e funcionais para os diferentes materiais, produtos e processos industriais (Rutschilling, 2008). define o designer de superfície como um profissional que desenvolve texturas visuais e táteis, visando a soluções estéticas e funcionais para cada contexto sociocultural e dentro de cada possibilidade de produção.

Segundo Rubim (2005), o design de superfície pode ser representado pelas mais diversas formas, desde que aceitemos que qualquer superfície pode receber um projeto. Ainda segunda a autora, suas principais aplicações são no setor têxtil, no de cerâmica, porcelana, plástico e papel. O vidro e o emborrachado são considerados interessantes, porém são pouco explorados. Enfim, quaisquer tipos de modificações aplicadas em uma superfície preparada para receber informações visuais e táteis são ações que resultam em design de superfície.

A superfície de um objeto influencia as emoções e a percepção que um consumidor adquire sobre determinado produto, despertando no indivíduo sensações e atitudes que podem reforçar o desejo do consumo. E dentre as áreas de trabalho no design de superfície, o setor têxtil é o que possui maiores subdivisões e possibilidades.

Pode-se explicar a prática da interferência de superfície o conjunto de ações realizadas em cima da estrutura do tecido com fins estéticos. Para a Surface Design Association - DAS, situada nos Estados Unidos, há um grande interesse em renovar a 
superfície têxtil através de técnicas artesanais e novos materiais para a criação de uma nova expressão pessoal e estética (LEVINBOOK, 2008).

O design de superfície em estamparia têxtil consiste na impressão de desenhos e imagens sobre o tecido, assumindo um papel importante no mercado de moda, visto que os tecidos estampados tornam-se um diferencial de seus produtos. Há inúmeras formas de executar processo de interferência de superfície nos tecidos, dentre elas: estamparia, tecelagem, jacquard, malharia e bordados tanto industriais como manuais. Assim é possível delimitar algumas características de cada tipo de trabalho, exercida sobre a superfície do tecido e suas formas diferenciadas que vão resultar em diferentes efeitos (RUTSCHILLING, 2008).

Uma das técnicas de interferência de superfície que também vale citar é a tecelagem, que é caracterizada pelo entrelaçamento de fios dispostos verticalmente, chamado urdume, com fios horizontais, as tramas, de forma a se obter um tecido com diferentes composições.

Outro processo de interferência de superfície é o Tie Dye, trata-se de um processo de tingimento com resultados de estampas graduais. Tie dye significa 'amarrar e tingir', a técnica consiste em fazer amarrações no tecido para que o corante penetre apenas nas extremidades, de modo a formar desenhos e estampas exclusivas. Por se tratar de um processo manual são encontradas variações de colorações e amarrações distintas nas peças, quando estas são produzidas em massa. Com estes conceitos a interferência de superfície ocorre tanto em relação a diferenciação do trabalho por meio da matéria-prima como também com a finalidade de desenvolver ferramentas de comunicação que reforcem valores estéticos (RUTSCHILLING, 2008).

\section{Design de Estamparia Têxtil}

O design de estamparia têxtil trabalha com a área criativa de caráter extremamente prático, dinâmico e amplo, que abrange moda, design de interiores, design gráfico, arte têxtil e artesanato. De acordo com Briggs-Goode (2014), os designers de estamparia têxtil criam imagens, estampas e cores que afetam diretamente a estética de um produto, essa especialidade que pode ser aplicada a superfícies têxteis, 
tanto de efeitos bidimensionais, sendo esta a estamparia, quanto de forma tridimensional, a qual compreende aplicações e interferências na estrutura de um tecido.

A estamparia têxtil teve início desde os primórdios como meio de manifestação cultural e artística. Geralmente recebe o nome de "motivo", no qual é composto de uma ou mais cores nas quais se repetem com regularidade sobre o fundo (YAMANOE, 2008).

Estamparia é o processo de impressão de estampas (desenhos desenvolvidos a partir de softwares gráficos) sobre o tecido, podendo ser rapport, com a repetição do desenho ao longo da superfície do tecido, ou projetada para ser inserida em partes específicas de uma peça, representando um desenho único (estampa localizada).

A estampa torna os tecidos mais atraentes e originais, sendo um dos grandes recursos utilizados no Design de Superfície. Além disso, diferencia o produto, despertando o desejo de consumo em quem se identifica com o conceito e símbolo traduzidos pelas suas composições gráficas.

A estamparia é um método por meio do quais grandes estilistas conseguiram se consagrar no mercado dando exclusividade às suas criações. Com isso, as técnicas para estampar tecidos evoluíram muito e hoje se encontra tecnologias como cilindros rotativos, transfer e estamparia digital. A partir dos processos conhecidos de estamparia industrial: quadros, cilindros e impressão à jato de tinta, pode-se criar diversos desenhos como modo de aplicação diferenciadas (PETRY, M. C.; ABREU, J. A. P., 2011).

A configuração da Superfície tornou-se [...] muito relevante. Já que a aparência é
percebida por meio das características diretamente observáveis pelos sentidos e
interpretáveis a nível pessoal, é crucial enfatizarmos tanto os aspectos sensitivos
inerentes quanto os cognitivos existentes - na interação do sujeito com o objeto através
da sua Superfície. Tais aspectos podem condicionar a percepção do sujeito sobre um
produto bem como as questões emocionais inerentes, influindo na mais valia e na
aquisição ou não do mesmo [...], pois os elementos percebidos pelos sentidos, além de
agregarem valor estético, definem e qualificam um artefato [...] (SCHWARTZ, A. R. D,
2008, p. 36).

No processo de estamparia têxtil, existem vários tipos de técnicas de transferência da estampa para o tecido. Conforme Briggs-Goode (2014) essas técnicas são: Batik, onde a imagem é estampada utilizando material como cera para proteger o tecido antes de tingir; processo de gravura em relevo, como estamparia em blocos de madeira (ou xilogravuras); gravura ou entalhe, como placa de cobre ou cilindro rotativo; estamparia por termo transferência, finalizada com uma fonte de calor; técnicas de 
estêncil, por exemplo, a mais utilizada que é a serigrafia; e, a mais recentemente, estamparia digital, que utiliza um processo de jato de tinta de uma impressora. A escolha de cada processo define o modo como cada estampa será transferida para o tecido, pois cada tecnologia envolvida na estampa cria efeitos visuais únicos de imagens, texturas e cor.

O processo de estamparia em quadros é conhecido como serigrafia ou silkscreen, que significa tela de seda. O seu aparecimento foi no Oriente Médio desde o século VIII, as telas eram gravadas na seda e emolduradas com caixotes de madeiras, por se tratar de matéria-prima leve. A gravação é feita por processo fotográfico, segundo o qual pequenos pontos são vazados na superfície do quadro por onde a cor passa a encontrar o tecido. Para a definição do desenho devem-se gravar várias telas, onde cada tela corresponde a uma cor que se encontra no desenho digital (LEVINBOOK, 2008).

As estampas corridas são conhecidas também como rapport, é uma palavra de origem francesa que se traduz por relação ou repetição. Possui uma continuidade nos desenhos por módulos, sem começo e fim. Para que isso ocorra é necessário elaborar a arte da estampa de modo que os desenhos se encaixam nas extremidades superiores, lateral e inferior nas dimensões das telas dos quadros (YAMANOE, 2008).

Para que se tenha uma melhor localização do rapport é necessário identificar ao design quais peças serão feitas na estampa, para que os moldes sejam encaixados corretamente no sentido da altura. Sendo assim, o desenho deve ser montado nos dois sentidos. Há vários tipos de rapport, específicos para cada processo desejado. Os tipos mais comuns são: direito, 1/2 saltado: horizontal e vertical, rapport especial: listra e barrado. 
Figura 1: Rapport.

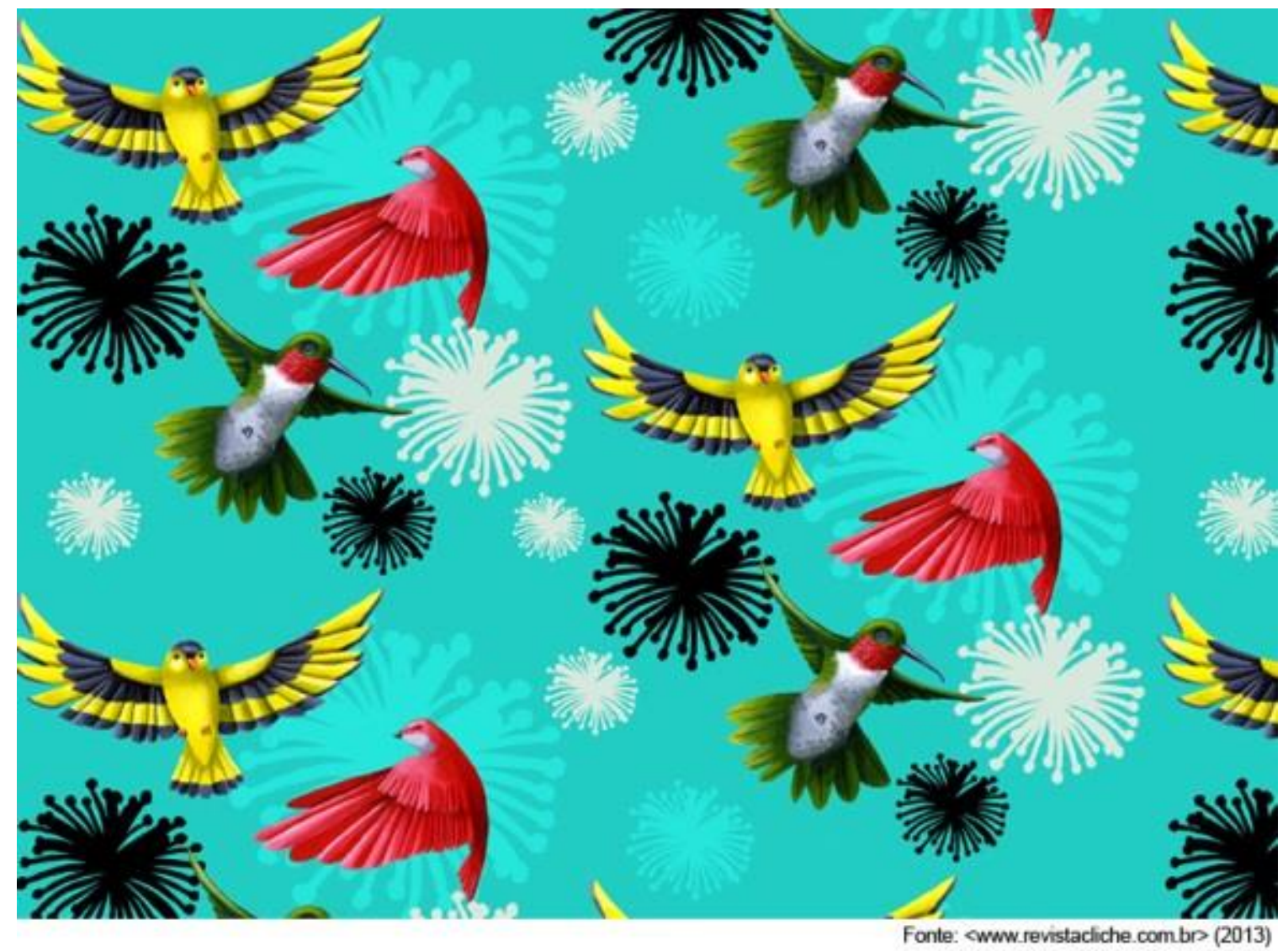

Este processo de estamparia manual é pouco usado para grandes volumes por se tratar de um processo lento e demorado, aumentando assim o custo final do produto. Quando há necessidade de estampar grande escala de produção recomenda-se o processo de quadro automático (LEVINBOOK, 2008).

O processo de estamparia localizada é o mesmo do de quadro corrido, sua diferença é em proporção ao tamanho, pois é uma técnica que será aplicada em uma peça confeccionada ou cortada. Para este processo não há preocupação com rapports visto que o processo de estamparia é feito direto na peça.

Há dois processos, o manual, feito com técnica silkscreen, a peça aberta é colocada na mesa e o estampador passa a régua de um lado para outro e em processo automático em que a máquina utilizada chama-se carrossel.

O processo da sublimação corrida, por exemplo, ocorre por meio de um cilindro metálico perfurado, e a diferença do processo de cilindro comum é na tinta utilizada, a máquina aplica a tinta sublimática para um rolo de papel que posteriormente será aplicado no tecido por uma prensa térmica. Do mesmo modo é feita a sublimação 
localizada, que é aplicada em peça confeccionada ou aberta, feita apenas em determinada área da superfície, ou seja, um desenho fechado sem repetições (SASSO, A. MEDEIROS, D. P., 2012).

Segundo (GIJON, 2008), no caso da estamparia por sublimação, geralmente é recomendada para se obter maior precisão nos detalhes, como estampar uma imagem fotográfica, para que este processo possa ser executado o tecido utilizado deve conter poliéster ou poliamida em sua composição, pelo fato da tinta sublimática agir diretamente com estas fibras.

Figura 2: Separação de Cor.

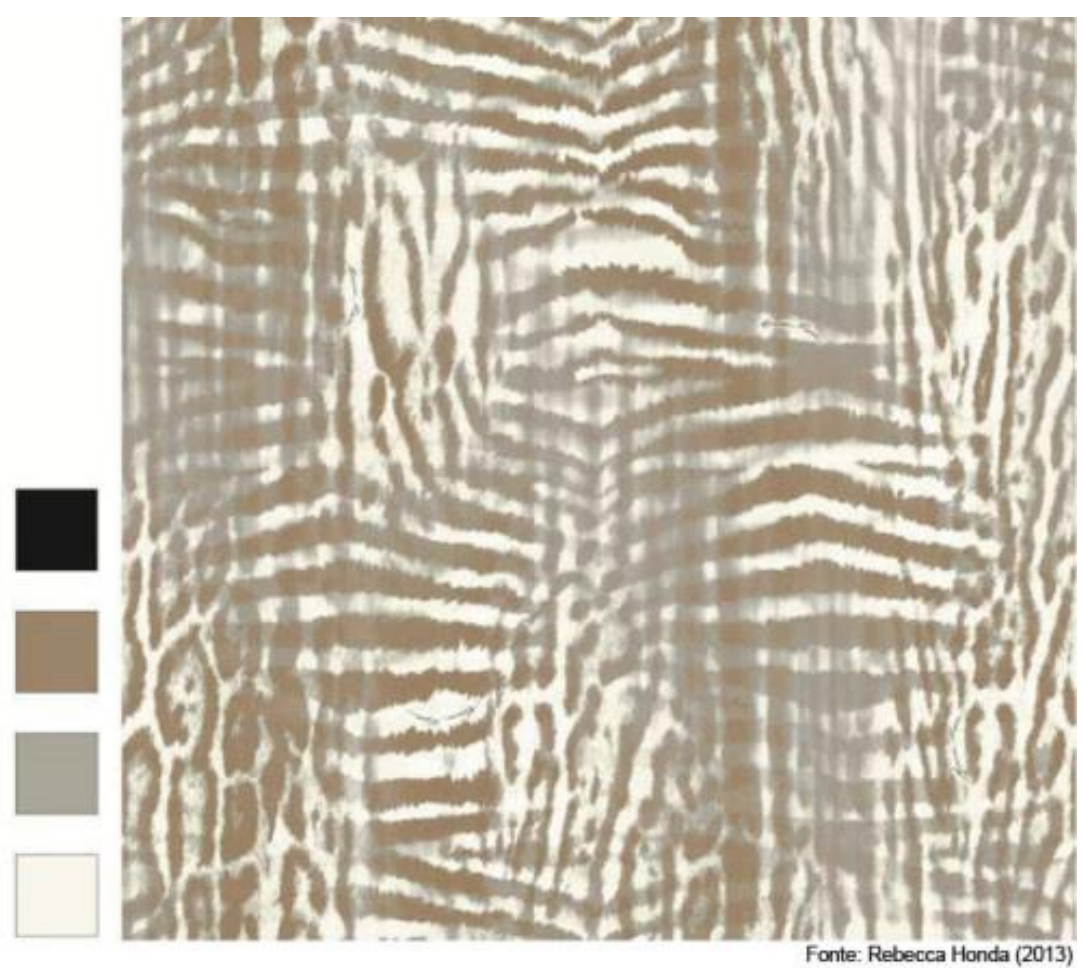

A estamparia digital é um processo que ocorre por meio de impressão de tinta direto no tecido, por impressoras grandes denominadas estamparia jato de tinta. Por meio do processo de digitalização da imagem que é a regulamentação de medidas, o desenho no computador é transferido para a impressora. O custo é mais alto que os processos convencionais de quadros e cilindros, mas a qualidade da estampa que se consegue atingir é perfeita (LEVINBOOK, 2008).

Dentro do design de superfície, a estamparia têxtil pode ser aplicada em 
diferentes segmentos como a moda e arte, tendo grande potencial para ser utilizado como instrumento inclusivo para o design de moda.

\section{Moda Inclusiva}

O termo moda inclusiva abrange a moda para todos, inclusive às pessoas com mobilidade reduzida, auxiliando-as a se vestirem e despirem com mais facilidade no dia a dia. $\mathrm{O}$ design das peças, através de fechamentos e aberturas colocadas estrategicamente em peças de roupas que normalmente pessoas com deficiência teriam dificuldade em manusear e atualmente, na área da moda inclusiva no Brasil, a indústria têxtil começa a se preocupar em confeccionar algo voltado para a inclusão social. No entanto, o conceito de ser inclusiva, muitas vezes, implica em torná-la exclusiva, pelo fato de se preocupar somente com o deficiente e não com o público em geral. Idealmente a moda inclusiva deve ser democrática, abrangente e acessível tanto nas lojas, quanto no custo, pois de nada vale criar moda inclusiva com preços abusivos, não acessíveis à maioria dos deficientes do país, que representam 45 milhões de pessoas, em sua maioria trabalhadora, consumidores da classe média.

Diante da necessidade de empresas voltadas para esta fatia do mercado, surgiram no Brasil algumas ONGS e concursos dispostos a incentivar a criação de moda adaptada para as pessoas com deficiência. Um deles é o evento Moda Inclusiva que acontece anualmente e é promovido pela Secretaria dos Direitos da Pessoa com Deficiência do Estado de São Paulo, que premia seus participantes com metragem de tecido, fomentando a produção na área. A moda inclusiva deve atingir a todos conforme (BATISTELLA, L. R., 2014, p. 7):

É preciso que pessoas com e sem deficiência tenham a oportunidade de comprar na mesma loja um produto com o mesmo estilo e conceito de elegância e funcionalidade, observando-se os preceitos de Desenho Universal, não apenas para vestir e enfeitas, mas também para conviver em sociedade.

O usuário com deficiência visual costuma orientar-se pelas formas e detalhes das roupas e para auxiliar a autonomia, adotam-se detalhes em relevos nas roupas para facilitar a identificação na hora da escolha e até da troca de roupa no cotidiano do deficiente visual. Roupas sem etiquetas ou lisas, sem muitos detalhes, atrapalham e 
confundem a pessoa com deficiência, podendo fazer com que ela vista a roupa de forma errada por não saber distinguir o lado certo da peça. Deste modo, este estudo visa auxiliar esta questão.

\section{Deficiência Visual e Moda: desafios para o Design Inclusivo}

O termo deficiência, de acordo com World Health Organization (1993) apud (Amiralian et al, 2000) conceitua como sendo uma perda ou anormalidade de estrutura a função psicológica, fisiológica ou anatômica, temporária ou permanente. Está inclusa nesta anomalia, defeito ou perda de um membro, órgão, tecido ou outra parte do corpo.

O design inclusivo trabalha a inclusão social, trata-se do compartilhamento de recursos, produtos e ambientes acessíveis por todos. É um foco direcionado também para quem possui algum tipo de deficiência ou mobilidade reduzida. Para um bom projeto na área do design inclusivo, de acordo com Barbosa et al (2010), é preciso a comunicação com o usuário, e também a comunicação do usuário com o produto adquirido. Uma vez que os olhos e ouvidos são os maiores receptores de informação, sendo assim, as pessoas que possuem deficiência visual ou auditiva são as mais prejudicadas neste sistema de comunicação.

Conforme (Margolin, 2004), um dos objetivos do design para o mercado é criar produtos para a venda. De modo contrário, o objetivo primordial do design social é a satisfação das necessidades humanas.

As pessoas com deficiência visual, mesmo não podendo enxergar o mundo em sua volta, podem interagir com este a partir da percepção desenvolvida dos outros sentidos. Isto tem implicações para o design de moda inclusivo: ao projetar um produto de moda, o designer pode, através da utilização de informações por meio de outros sentidos (tátil, por exemplo), pode facilitar tanto a escolha quanto o uso do produto.

Atualmente, conforme dados do Instituto Brasileiro de Geografia e Estatística (IBGE), representa $18.3 \%$ da parcela da população brasileira de acordo com dados do IBGE de 2014. De acordo com estimativas, este número poderá chegara em 2020 a 75 milhões de pessoas no mundo com deficiência visual Brito et al (2010).

Em geral, há três principais tipos de classificações para a deficiência visual: baixa visão, cegueira parcial e total. A cegueira pode ser congênita ou adquirida, a 
primeira seria desde o nascimento, a última por sua vez, pode desenvolver dependendo da região que é produzido o dano que ocasiona a visão, que de acordo com Mosqueira, (2014) pode ser nas estruturas transparentes do olho, que ocasiona a catarata e torna a córnea opaca. Também pode ser na retina proporcionando retinose pigmentaria. Ocorre também no nervo óptico, comum em casos de diabetes ou glaucoma. E, também pode ser devido a danos ocasionados no cérebro, estes em geral costumam ser mais graves e ocasionar a cegueira total.

O sistema Braille, utilizado por pessoas com deficiência visual, foi inventado por Louis Braille em 1825 com base em um código militar com o objetivo de facilitar a comunicação noturna. Segundo Canejo (2005), apud Pacheco et al (2014) o Braille é um tipo de leitura e escrita em relevo do qual é composto por 64 símbolos por meio de seis pontos posicionados em variadas posições ao longo de três colunas. Ele também possui 63 sinais e também é utilizado na matemática e em partituras de música.

Figura 3: Partitura de música em braille

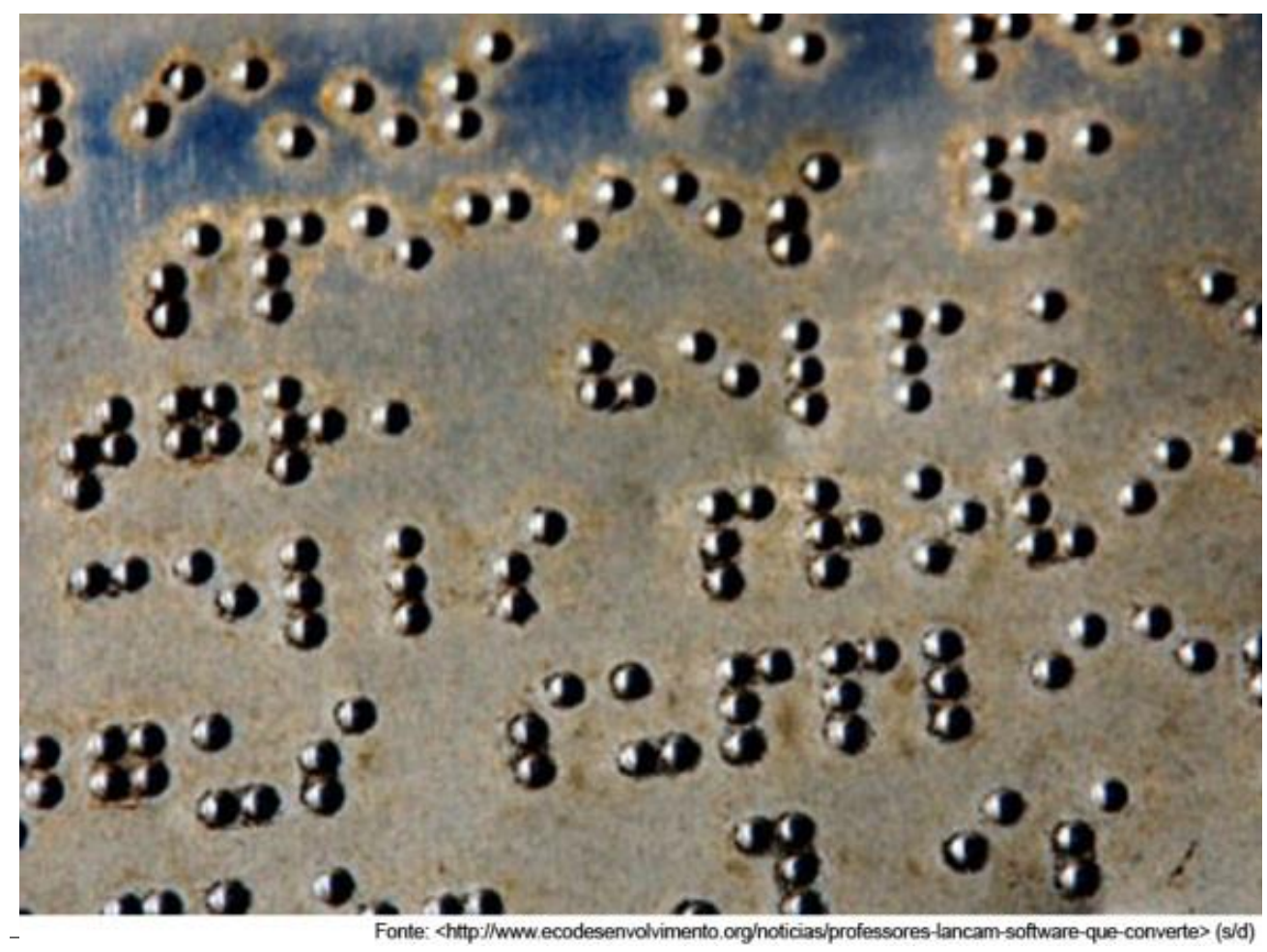

Conforme Vygotsky (2007), a percepção dos deficientes visuais ocorre por meio dos sentidos. O universo vai além dos cinco sentidos, uma destas percepções 
desenvolvidas pelos deficientes visuais pode-se chamar de percepção háptica, o tato dinâmico, reconhece as propriedades necessárias dos objetos para manuseio, tais como carregar uma caixa ou erguer um copo.

Figura 4: Alfabeto em braille

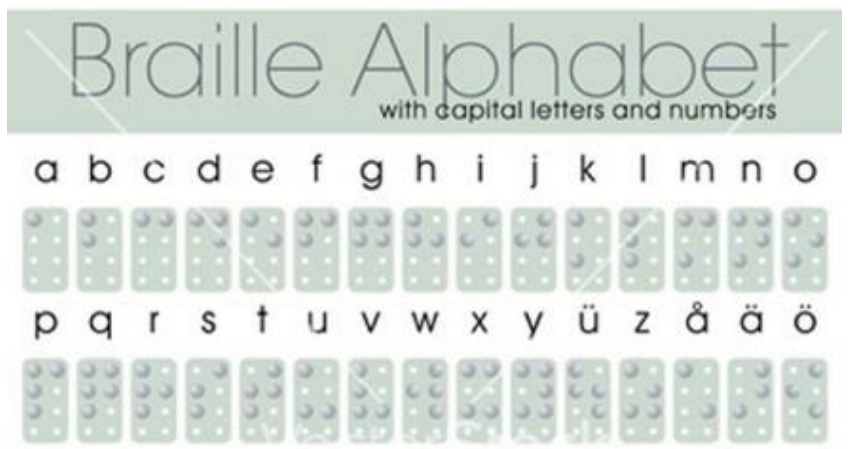

A B C D E F G H I J K L M N O

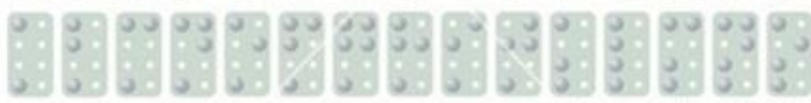

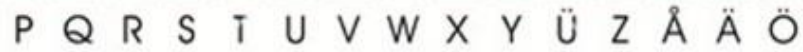

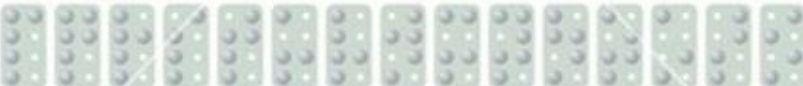

! ( )*, - : : ? 0123456789

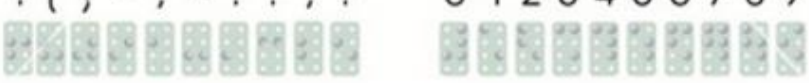

Fonte: \&http://www.vectorstock.com/royalty-free-vector/braille-alphabet-vector514799> (s/d)

De acordo com Boff (2012) apud Vigotski (1997), quando o sujeito perde a visão na fase da adolescência, é evidente que se torna menos complexo para lidar com a deficiência comparada a um sujeito que nasce com esta condição, isto porque já tem os conceitos e abstrações formadas. Deste modo, o alfabeto braile se tornou um modo de inserir a pessoa socialmente. Para o design de moda inclusiva, o uso do sistema Braille pode contribuir no sentido de fornecer informações relevantes que facilitem a pessoa com deficiência visual tanto no processo de escolha, uso e manutenção da peça de vestuário.

As percepções dos aspectos estéticos ou simbólicos de um produto podem ser identificadas por meio de certas propriedades. Para Neves et al (2014), "No produto de 
moda, essas atribuições são perceptíveis por meio de propriedades físicas dos materiais utilizados, tais como formas, cores, sons, texturas, odores ou temperaturas, bem como dos elementos simbólicos empregados"

Segundo Grave (2004), a roupa deve proporcionar conforto de modo que seu dia a dia ao colocá-la não deve ser lembrado como algo que deve ser tirado como se libertasse do "estresse". Ela deve ser facilitadora para pessoas com deficiência, seja em aspectos ergonômicos tais como desde o momento de colocar a roupa e tirá-la, como também de escolhê-la no processo de compra. Deve ser considerada mobilidade, textura, maleabilidade, medidas, caimento, etc. Todos estes são detalhes relevantes na usabilidade. Apesar de o mercado oferecer algumas soluções, tais como o caso da etiqueta de roupa especial para deficientes visuais, ainda carece de inovações no quesito citado acima. Isto porque ainda não há lei que obrigue as empresas a desenvolverem estas etiquetas ou mesmo desenvolver peças voltadas ou aprimoradas para este público. Esta etiqueta trata-se de um material emborrachado em braile de modo que descreve a cor do produto, o diferencial dela é que consegue proporcionar algumas informações necessárias sem ocupar muito espaço, isto porque o braile ocupa mais espaço que uma escrita normal (FRANÇA, 2011).

Figura 5: Etiqueta desenvolvida em braile.

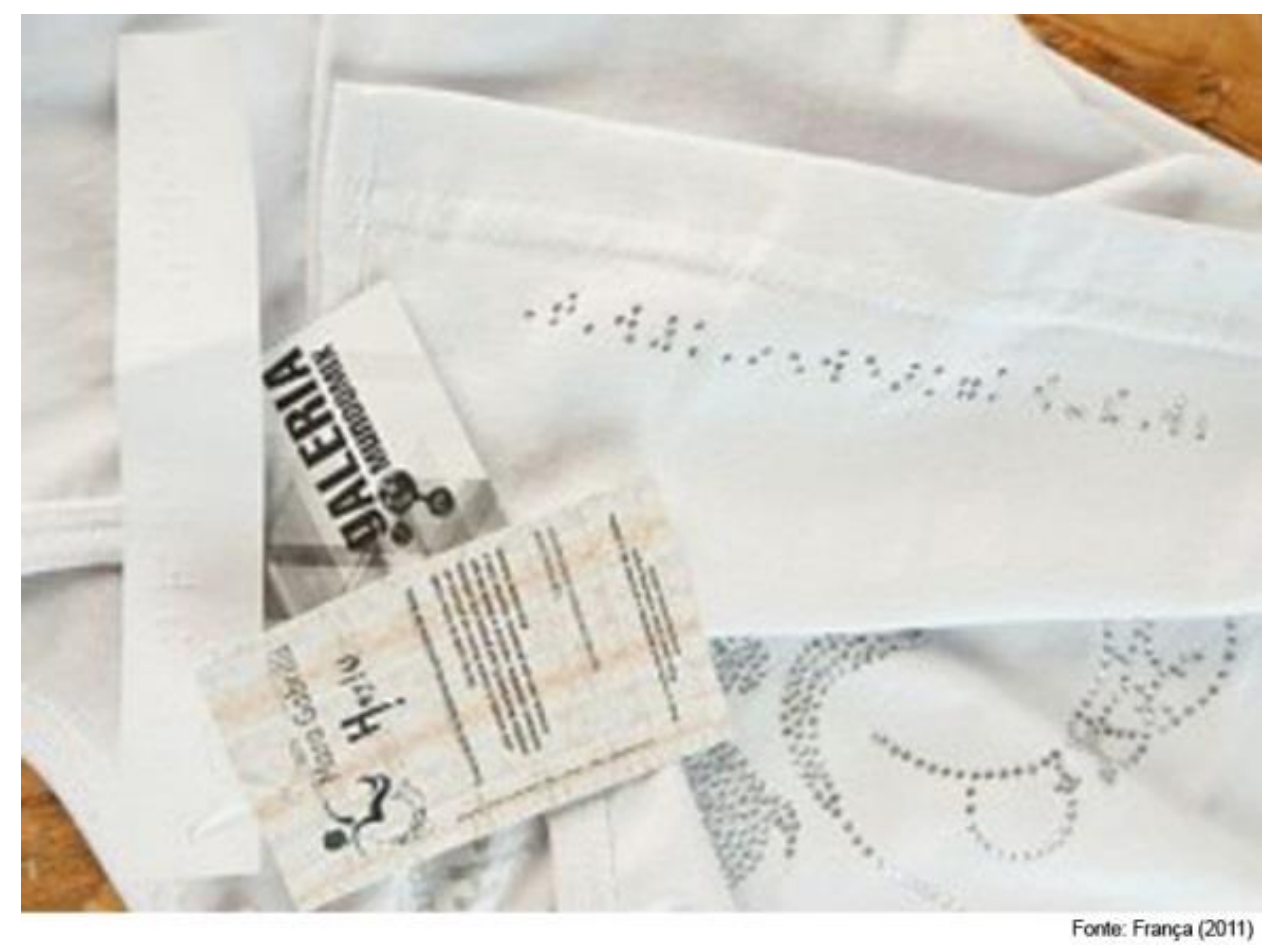


Algumas designers de moda desenvolveram coleções voltadas para este público, o que mostra que alguns profissionais observaram a carência desse segmento. Um exemplo é o caso da designer Charlotte Pringels, que se inspirou em um filme holandês denominado "Blind", lançado no ano de 2007. O seu interesse foi tentar fazer com que o tato levasse o indivíduo a ver ou ao menos tentar desenvolver os demais sentidos. Em seu depoimento: "Foi um grande desafio para mim, porque não era apenas um conceito, mas um sentimento. Eu tentei lidar com os materiais para torná-los legíveis, identificáveis pelo uso de diferentes texturas, como lã, camurça, veludo... mas também os tornando literalmente legíveis com inscrições em Braille e o uso de impressões de socorro" (ALBUQUERQUE, 2013).

Figura 6: Peças desenvolvidas em braile.

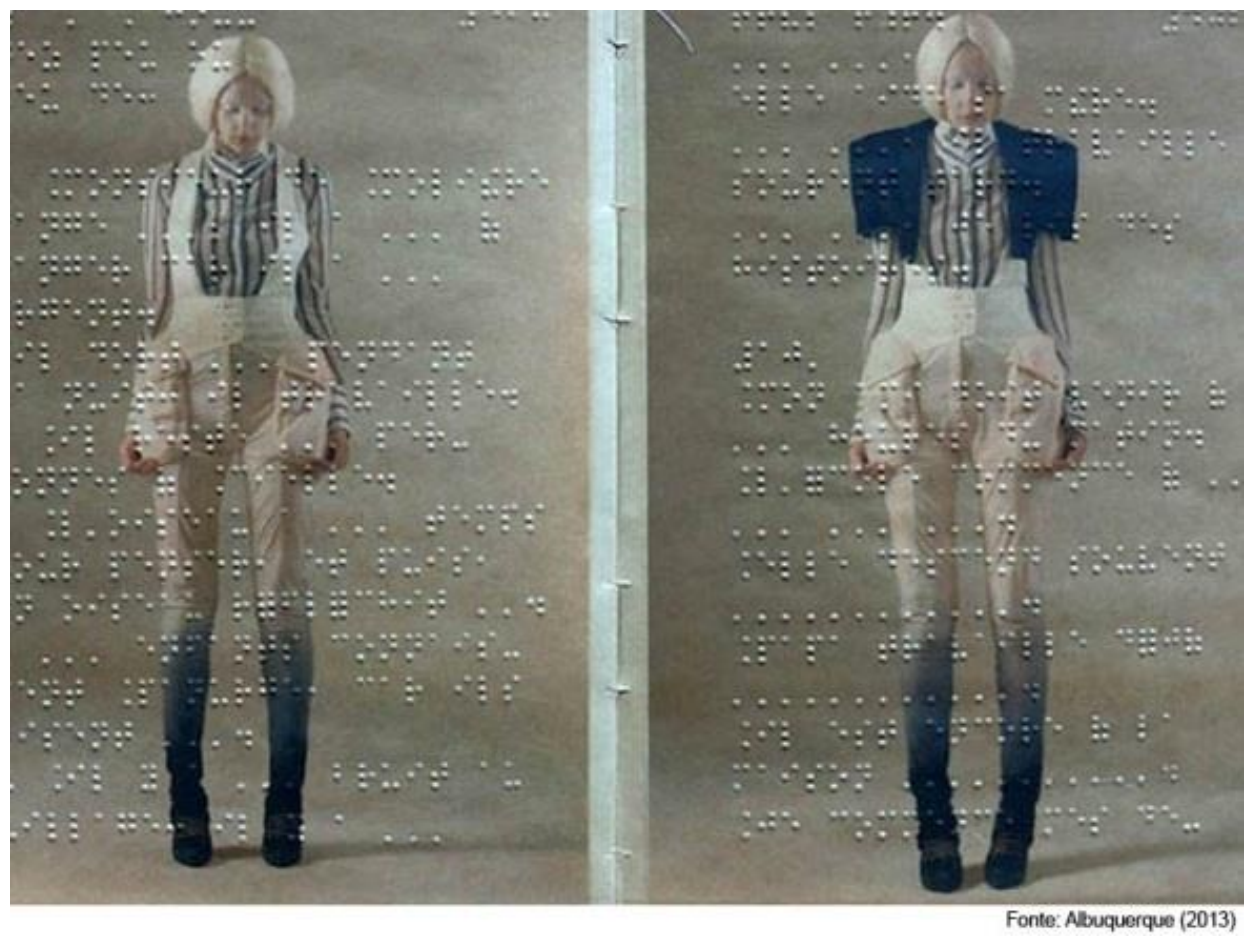

\section{Materiais e Métodos}

A pesquisa a ser realizada neste trabalho pode ser classificada como base para moda inclusiva com foco em deficiente visual porque o assunto ainda é pouco estudado e o procedimento deste trabalho se realiza por meio de vivência com o usuário para entender a real necessidade e melhor solucionar o problema.

A pesquisa teve como base a tecnologia assistiva com o propósito de adaptar 
roupas que já existem com detalhes em braile ou relevo, aliada ao design universal, sempre pensando em concluir o desenvolvimento de uma peça, para atingir o maior número de usuários possível, sem distinção de mobilidade ou deficiência, pois com estes detalhes o deficiente visual poderá identificar mais facilmente suas próprias vestes e ser mais autônomo na hora de escolhê-las.

A pesquisa utilizará o design universal, tecnologia assistiva e o design de superfície para criar uma moda inclusiva mais abrangente do que a atual existente e estas ferramentas permitem que ao projetar ou adaptar uma peça de roupa para um usuário deficiente visual, estejamos mais próximo da solução devido ao convívio com o usuário. O material documentado e suas análises servirão como componentes do estudo ergonômico e prático que se pretende construir.

No desenvolvimento da coleção serão desenvolvidas peças buscando envolver todos os demais sentidos, seja o tátil por meio do design de superfície, o olfato pelos tecidos aromáticos, ajudando a identificar a cor da peça não apenas pela etiqueta como também pela cor. Como estas pessoas acabam desenvolvendo mais os outros sentidos, como o sonoro, algumas peças terá uma harmonia com dispositivos sonoros que terá coerência com a coleção desenvolvida. Também será trabalhada a semiótica para que esta peça seja semelhante com qualquer outra peça, representando um design universal. Este processo foi desenvolvido com o auxílio do software CorelDraw, onde foram desenhados os croquis e especificações técnicas.

\section{Resultados e Discussões}

A partir das informações discutidas acima, foram desenvolvidas duas propostas de design de moda inclusiva, sendo escolhida a temática musical como contexto de trabalho. Os princípios inclusivos foram aplicados por meio do design de superfície e da abordagem funcional da peça, buscando facilitar também o processo de vestir-se.

Existe um projeto de lei para ser aprovado que faz com que seja obrigatório que as empresas tenham etiquetas em braile, isto demanda tempo até que seja executado e venha de fato a ocorrer na prática, os deficientes visuais ainda precisam se vestir e depender do auxílio de terceiros.

Com essa preocupação em garantir o aspecto inclusivo das propostas desenvolvidas, buscou-se utilizar detalhes em braile ou relevo, aliada ao design 
universal, buscando atingir o maior número de usuários possível, sem distinção. Estes detalhes buscam oferecer condições ao deficiente visual na identificação da peça, favorecendo sua autonomia também no processo de escolha. Para isto, as propostas foram desenvolvidas a partir dos conceitos de design inclusivo, design universal, tecnologia assistiva e o design de superfície (Figuras 3 e 4).

Figura 7: Vestido em braile.

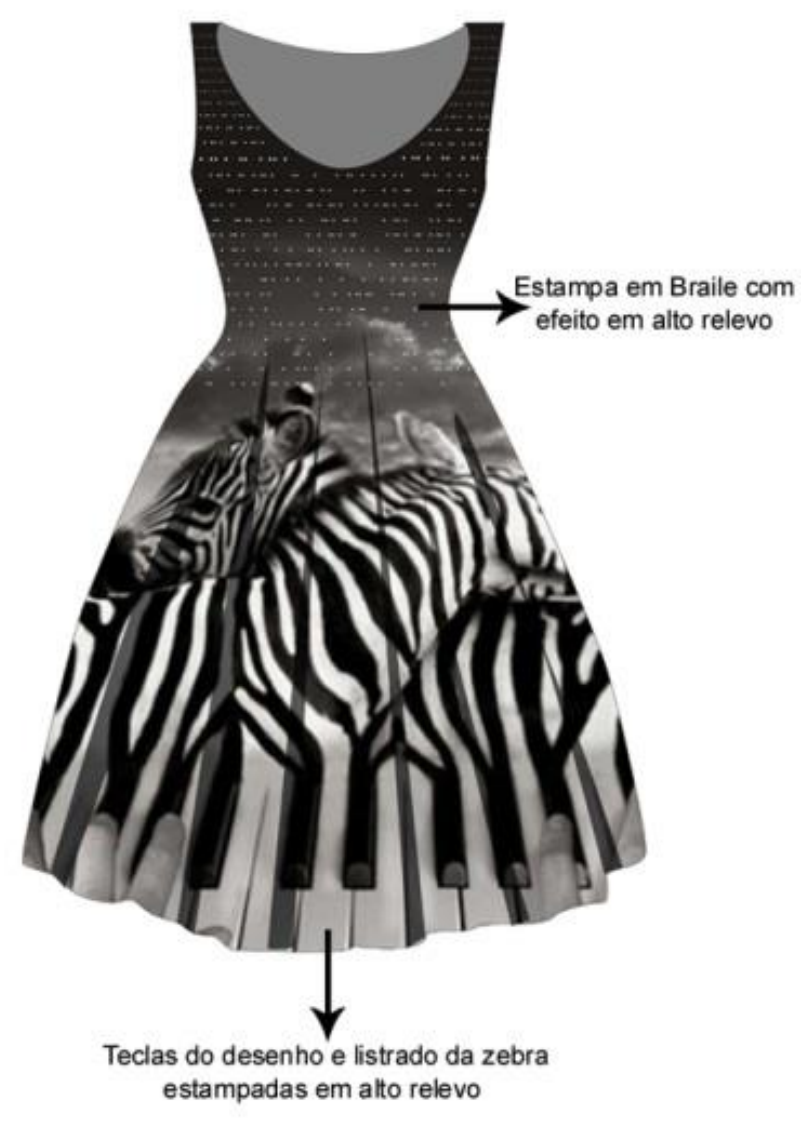

Fonte: Os Autores (2015)

A imagem da estampa de sublimação mescla com a escrita em braile remetendo a semiótica com a música Imagine do John Lennon em braile, trazendo uma imagem surrealista. E estampa flocada de veludo nas teclas de sustenido (teclas pretas). 
Figura 8: Camiseta em braille

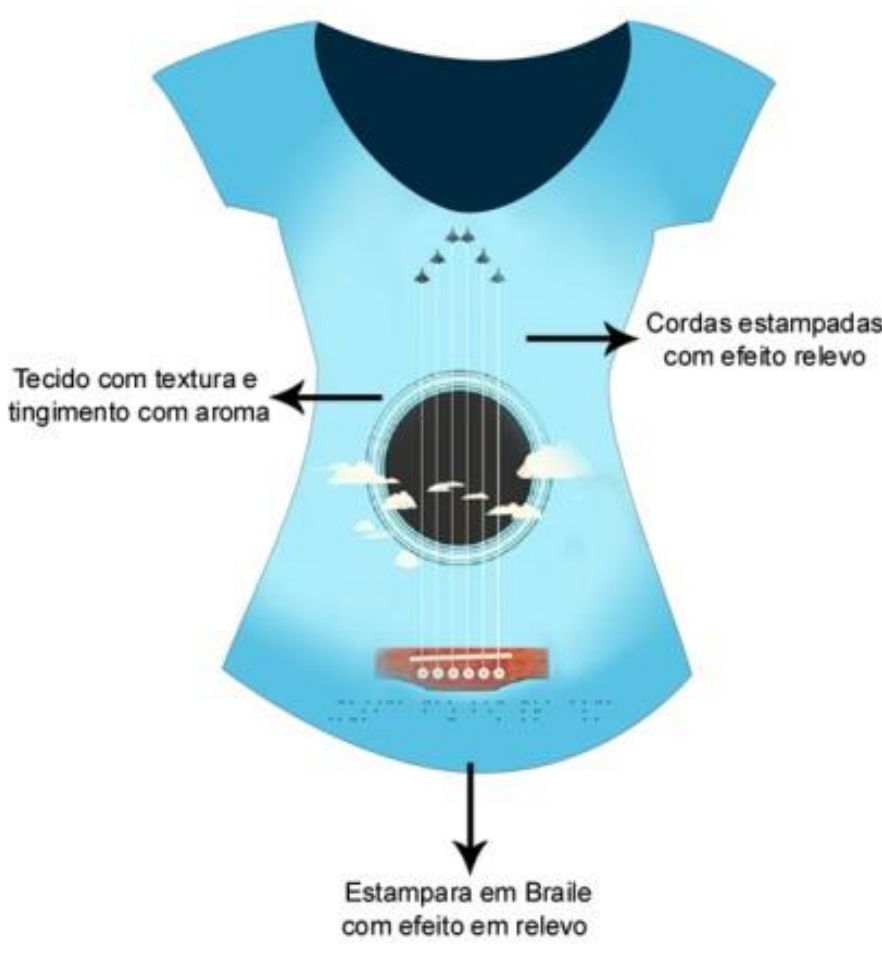

Fonte: Os Autores (2015)

Como podem ser observadas nas Figuras 3 e 4, as propostas de moda inclusiva desenvolvidas buscou na sensibilidade tátil a solução para oferecer autonomia às pessoas com deficiência visual, sem, entretanto diferenciar a peça ou caracterizá-la como unicamente destinada a um público específico, uma vez que isto eliminaria seu aspecto inclusivo.

As peças possuem estampa em relevo e escrita em Braille. Vale ressaltar que outros sentidos também podem ser trabalhados na moda inclusiva, como por exemplo, o olfato, através dos tecidos aromáticos, ajudando a identificar a cor da peça não apenas pela etiqueta. Ainda, o uso de estímulos sonoros pode também ser utilizado e ter sua relevância na usabilidade e satisfação do usuário com as peças de roupa.

Uma próxima etapa do trabalho é o desenvolvimento de protótipos das peças para estudo ergonômico, a fim de se verificar os aspectos práticos e funcionais e suas 
implicações na autonomia e independência do usuário, tanto na seleção quanto no ato de vestir-se.

\section{Considerações Finais}

Com toda tecnologia existente no mercado, ainda há muito a ser explorado e estudado no que diz respeito ao design de moda para pessoas com deficiência visual. De forma geral, as empresas que inovaram, tiveram foco apenas em quesitos como etiqueta e, ainda assim, esta não proporciona todas as informações necessárias, além do fato de nem todo deficiente visual ter domínio na leitura braile. Além disso, as vestimentas existentes são direcionadas exclusivamente ao deficiente visual, deixando distante o sentido da universalidade, segundo a qual o produto deve ser atender às necessidades e expectativas de todos, sem diferenciações.

O presente estudo apresentou duas propostas de peças projetadas com base no design inclusivo, fundamentadas em um levantamento bibliográfico que identificou os aspectos relevantes para os deficientes visuais nos produtos de moda - vestuário. As peças projetadas contemplam a inclusão e universalidade, uma vez que possuem atributos físicos (estampas em relevo e detalhes em braile) que favorecem e facilitam o deficiente visual no processo de escolha e uso das peças. Tais atributos foram utilizados mantendo-se uma preocupação com a estética da peça, de forma a não diferenciá-las ou torná-las "exclusivas". Houve uma preocupação no sentido de que as peças possam ser desejadas e utilizadas por todas as pessoas, e não para um público específico. Para atender de forma mais adequada às necessidades e expectativas das pessoas com deficiência visual, é importante que o design de moda considere não apenas as questões estéticas da peça, mas também os aspectos práticos, uma vez que são altamente relevantes para garantir a eficiência e satisfação no processo de vestir-se.

O uso de detalhes em relevo, braile e texturas podem contribuir no auxílio da autonomia e no aumento da autoestima do deficiente visual, melhorando suas condições de independência durante uma compra em uma loja comum. Ainda, é necessário que a implementação destes aspectos na peça não resulte em diferenciação estética, podendo ser comercializada sem distinção. Neste sentido, o presente estudo destacou a relevância do tema diante da demanda e da carência neste ramo do vestuário. Novas pesquisas sobre o tema devem explorar as relações entre as diferentes propostas de vestuário e 
suas implicações nas percepções de pessoas com deficiência visual com relação aos aspectos estéticos, funcionais e de conforto.

\section{Agradecimentos}

Os autores prestam seus agradecimentos à CAPES (Coordenação de Aperfeiçoamento de Pessoal de Nível Superior).

\section{Artigo recebido em Outubro de 2015. Aprovado em Dezembro de 2015 \\ DOI:http://dx.doi.org/105965/1982615x09012015115}

\section{Referências}

IBGE. Censo 2010. Disponível em: <http://www.ibge.gov.br/home/estatistica/populacao/censo2010/default.shtm>.

CALDERÓN, G. C. 2010. ESTAMPARIA: O processo criativo do designer gráfico a elaboração de estampas para uma coleção de moda. Universidade Federal de Pelotas, Pelotas. $9^{\circ}$ Congresso Brasileiro de Pesquisa e Desenvolvimento em Design.

RUTSCHILLING, E. A. 2008. “Design de superfície. Porto Alegre”: ED. da UFRGS. 104 p.

RUBIM, R. 2005. “Desenhando a Superfície”. Edições Rosari: São Paulo.

LEVINBOOK, M. 2008. "Design de superfície: técnicas e processos em estamparia têxtil para produção industrial”. 105 p. Dissertação (Mestrado em Design). Programa de Pós-Graduação Stricto Sensu, Universidade Anhembi Morumbi, São Paulo.

BRIGGS-GOODE, A. Design de Estamparia Têxtil. Porto Alegre: Ed Bookman,2014.

YAMANOE, L. A. Estamparia Têxtil. USP. São Paulo, 2008. Disponível em: $\langle$ http://www.teses.usp.br/teses/disponiveis/27/27159/tde.../5281852.pdf >. Acesso em 05 mai. 2015.

PETRY, M. C.; ABREU, J. A. P. 2011. "Reflexões sobre o Mercado de Design para Estamparia Têxtil no Rio de Janeiro". In: Redige, v. 2, n. 1. SENAI: Rio de Janeiro. Disponível em: <http://www.cetiqt.senai.br/ead/redige/index.php/redige/article/viewArticle54>. Acesso em 30 abr. 2015.

SCHWARTZ, A. R. D. "Design de Superfície: por uma visão projetual geométrica e tridimensional". 2008. Dissertação (Pós Graduação em Desenho Industrial) - Universidade Estadual Paulista, São Paulo. 216 p. 
SASSO, A. MEDEIROS, D. P. Design de superfície, moda e tendência: Relações e multidisciplinaridade criativa. 2012. In: Anais do $1^{\circ}$ CIMODE. Congresso Internacional de Moda e Design: Guimarães, Portugal. Guimarães: Unminho. p. 336-344.

GIJON, A. Estamparia corrida. 2008. Disponível em: http://www.fashionbubbles.com/historiada-moda/estamparia-corrida-parte-33/. Acesso em 26 out 2013.

BATISTELLA, L. R. 2014. "Moda inclusiva: Considerações e Novidades no Projeto de Vanguarda da Moda Brasileira". São Paulo: Catálogo de Moda Inclusiva.

World Health Organization. "International classification of impairments, disabilities, and hadicaps: a manual of classification relating to the consequences of disease". Geneva: 1993.

AMIRALIAN M. LT. PINTO. E. B. GHIRARDI M. IG. LICHTIG. I. MASINI. E. FS. PASQUALIN. L. 2000. "Conceituando deficiência". Ver. Saúde Pública, 34 (1): 97-103. Disponível em: <http:www.fsp.usp.br> Acesso em: 03 mai 2015.

BARBOSA, M. B.; ALBUQUERQUE, R. de M. A. 2010. "Comunicação, Sinalização e Acessibilidade". In: PRADO, A. R. de A.; LOPES, M. E.; ORNTEIN, S. W. (Org.) "Desenho Universal: caminhos da acessibilidade no Brasil”. São Paulo: Annablume. p. 279-290..

MARGOLIN, V; MARGOLIN, S. "Um modelo Social de Design: questões de prática e pesquisa". 2004. Revista Digital em Foco, V. 1, n 001, Salvador: Universidade do Estado da Bahia.

BRITO, I. J. G; JARDIM, M. D. P; CARDOSO, A. M; MING, W. C. 2010. "O design de moda como inclusão social de portadores de deficiência visual". Revista Eletrônica de Educação e Tecnologia de Senai - SP. ISSN 1981-8270. V. 4. N. 9, out 2010.

MOSQUEIRA, C. 2014. "Deficiência visual: do currículo aos processos de reabilitação". Curitiba: Editora do Chain, 232 p.

CANEJO, Elizabeth. 2005. "Apostila introdução ao sistema Braille". Fundação de Apoio à Escola Técnica - FAETEC. Diretoria do Desenvolvimento da Educação - Gerência de Programa de Inclusão. Governo do Estado do Rio de Janeiro.

PACHECO, M. S.; MEDEIROS, D. P.; GONÇALVES, M. M. Design Inclusivo: Criação de estampas em prol da inclusão social. 2014. $11^{\circ}$ P\&D Design, Congresso Brasileiro de Pesquisa e Desenvolvimento em Design, Gramado.

L. S. VYGOTSKY. 2007. “A Formação Social da Mente”. São Paulo: Martins Fontes.

BOFF, A. P. "O Aprendizado da escrita braile por meio dos dizeres da pessoa com cegueira adventícia na fase adulta". FURB, IX ANPED SUL, 2012.

VIGOTSKI, L. S. 1997. “Obras escolhidas. Fundamentos da defectologia”. Madrid: Visor.

NEVES, E. P.; PASCHOARELLI, L. C.; MENEZES, M. S. dos. 2014. Moda e ergonomia: Contribuição emocional à percepção do vestuário. $14^{\circ}$ Ergodesign, USIHC. Congresso 
Internacional de Ergonomia e Usabilidade de Interfaces Humano-Tecnologia: Produto, Informações, Ambiente Construído e Transporte. ISBN 978-85-8209-028-02. Joinville.

GRAVE, M. F. de. 2004. A modelagem sob a ótica da ergonomia. Zennex Publishing: São Paulo, SP. 103 p.

FRANÇA, V. Etiqueta em braile deixa moda mais acessível. Publicado em 20 jan 2011. Disponível em: <http://sao-paulo.estadao.com.br/noticias/geral,etiqueta-em-braile-deixa-modamais-acessivel-imp-,668553> Acesso em 05 jan 2015

ALBUQUERQUE, H. Coleção de roupas em braille. Publicado em 07 jun 2013. Disponível em:<http://www.bemparana.com.br/indumentaria/colecao-de-roupas-em-braille/> Acesso em 06 jan de 2015. 


\section{Bibliografia}

ABERGO. Associação Brasileira de Ergonomia. Norma ERG BR 1002 - Código de Deontologia Do Ergonomista Certificado. Outubro, 2003. Disponível em: $<$ http://www.abergo.org.br/arquivos/normas_ergbr/norma_erg_br_1002_deontologia.pdf Acessado em $21 \mathrm{dez} 2013$.

BARbOSA, M.J.S. (Org.). Passo e compasso: nos ritmos do envelhecer. Porto Alegre: EDIPUCRS, 2003.

BRASIL. Ministério da Saúde. Secretaria de Atenção à Saúde. Departamento de Ações Programáticas Estratégicas. Manual de Atenção à Mulher no Climatério/Menopausa/Ministério da Saúde, Secretaria de Atenção à Saúde, Departamento de Ações Programáticas Estratégicas. (Série A. Normas e Manuais Técnicos) (Série Direitos Sexuais e Direitos Reprodutivos - Caderno, n.9). Brasília: Editora do Ministério da Saúde, 2008;

CASOTTI, L.; CAMPOS, R.. Consumo da beleza e envelhecimento: histórias da pesquisa e de tempo. In: GOLDENBERG, M. (org.). Corpo, envelhecimento e felicidade. Rio de Janeiro: Civilização Brasileira, 2011, p. 109-131.

CASTILHO, K. Moda e Linguagem. São Paulo, SP: Editora Anhembi Morumbi, 2009.

CRONEY, J. Antropometria para diseñadores. Barcelona: Editorial Gustavo Gili, S.A, 1971.

FLÜGEL, J. C. A psicologia das roupas. São Paulo: Editora Mestre Jou, 1966.

GRAVE, M. F. A moda-vestuário e a ergonomia do hemiplégico. São Paulo: Escrituras Editora, 2010.

HALBE, A. F. P. Repercussões emocionais do climatério. In HALBE, H.W. Tratado de Ginecologia. 3a ed. São Paulo: Roca, 2000. 198-204 p.

IBGE. Instituto Brasileiro de Geografia e Estatística. Pesquisa de Orçamento Familiares 2008-2009: Análise do Consumo Alimentar Pessoal no Brasil. Rio de Janeiro: IBGE, 2011. Disponível em: <http://www.ibge.gov.br/home/estatistica/populacao/condicaodevida/pof/2008_2009_ana lise_consumo/pofanalise_2008_2009.pdf >. Acesso em: 12 mar. 2014.

IIDA, I. Ergonomia: Projeto e Produção. São Paulo: editora Edgard Blucher, 2005.

MATTHEWS, K.A. et al. Body mass index in mid-life women: relative influence of menopause, hormone use, and ethnicity. In: International Journal of Obesity and related metabolic disorders: Journal of International Association for Study of Obesity, London, vol. 25, n. 06, 863-873 p., jun. 2001. Disponível em: <http://www.ncbi.nlm.nih.gov/pubmed/11439301>. Acesso em: 12 mai. 2014.

ORSATTI, et al. Indicadores antropométricos e as doenças crônicas não transmissíveis em mulheres na pós-menopausa da região Sudeste do Brasil. In: Revista Brasileira de 
Ginecologia e Obstetrícia [online], Rio de Janeiro, vol. 30, n. 04, 182-189 p., abr. 2008. Disponível em: <http://www.scielo.br/pdf/rbgo/v30n4/05.pdf>. Acesso em 13 jan. 2014. 